\title{
Seroprevalence of Transfusion Transmitted Infections Among Blood Donors in a Tertiary Care Hospital in Andhra Pradesh
}

\author{
C R Sirajunnisa Begum¹, S Nafeesa Banu ${ }^{2 *}$ and Venkatraman $\mathrm{J}^{2}$ \\ ${ }^{1}$ Department of Pathology, Apollo Medical College, Murukambattu, Chittoor, Andhra Pradesh. India \\ ${ }^{2}$ Dept. of Pathology, Mahatma Gandhi Medical College and Research Institute, Pondicherry. India
}

\begin{abstract}
Background: Blood transfusion is a life-saving procedure as even a single unit of blood and its components can save multiple recipients in need. Though it's a safe procedure, the risk of transmission of infections like HIV, syphilis, hepatitis B and hepatitis C are still seen. The objective of this study was to determine the frequency of HBsAg, HCV, HIV, Syphilis and Malaria in various ABO and Rh (D) blood groups donors.

Methods: A retrospective study was performed from January 2014 to May 2017 in a blood bank of a tertiary care hospital. A total of 8260 blood units which were collected from both voluntary and replacement donors during the study period were included. Complete donor's demography and screening status forTransfusion Transmitted Infections(TTI's) were analysed.

Results: Out of 8260 blood donors, 232(2.8\%) were positive for TTIs. The overall prevalence of HIV, HBV, HCV and Syphilis was found to be $0.06 \%, 2.1 \%, 0.15 \%$ and $0.4 \%$ respectively. The highest percentage of prevalence was observed for HBV, followed by syphilis, HCV and HIV. Higher seroprevalence of TTI's were noted in replacement donors and younger age group between 18 to 30 years.

Conclusion: Following strict donor eligibility criteria and effecting high sensitive screening methods can bring down the prevalence of TTI's. Proper treatment and follow-up counselling can help in preventing further transmission of infections in the community.
\end{abstract}

Keywords: Transfusion Transmitted Infections, HIV, Syphilis, HBV, HCV

\section{Introduction}

Blood transfusion is a life-saving procedure as even a single unit of blood and its components can save multiple recipients in need. ${ }^{[1]}$ Though it's a safe procedure, the risk of transmission of infections like HIV, syphilis, hepatitis B and hepatitis $\mathrm{C}$ are still seen ${ }^{[2]}$ Over the past two to three decades, several measures have been introduced into the screening of blood donations to detect diseases that may be transmitted via blood transfusions with the aim of improving the quality and safety of the blood supply. ${ }^{[3]}$ It has been found that there was $1 \%$ chance of transfusion associated problems that can occur with every unit of blood. ${ }^{1}$ It is due to the factors such as immunologically variant viruses, inadvertent laboratory testing errors, disease in pre-seroconservation or window phase of the infection, highly expensive screening tests and immuno silent carriers. ${ }^{[1,4]}$

HIV has become a major problem to mankind and its prevalence and incidence is increasing day by day. India has a population of more than 1.2 billion with 5.7 (reduced to 2.5) million Human Immunodeficiency Virus (HIV) positive, 43 million $\mathrm{HBV}$ positive and 15 million $\mathrm{HCV}$ positive persons. ${ }^{[5]}$
The risk of transfusion transmission of these viruses may be alarming due to high seroprevalence of anti-HIV-1, anti$\mathrm{HCV}$, and $\mathrm{HBsAg}(0.5 \%, 0.4 \%$, and $1.4 \%$, respectively) in blood donors. ${ }^{[6]}$ The incidence of TTI is common in Asia and Africa whereas it is relatively rare in western countries. ${ }^{[7]} \mathrm{HCV}$ leads to 8000 to 10000 deaths annually in developed countries like US with an estimated global burden of 3.9 million people. ${ }^{[8]}$

In $50 \%$ of the patients with TTI, there is associated morbidity and mortality depending upon the number of transfusions received and underlying condition of the patient. ${ }^{3}$ Transmission of infection during the asymptomatic phase results in higher incidence of TTIs. This incidence can be reduced by regular implementation of donor selection procedures and donor screening by sensitive tests and effective inactivation procedures ${ }^{3}$ Both WHO and Indian National AIDS Control Origination (NACO)also recommends comprehensive screening for all blood donations, using a quality control system to screen for HBV, HCV, HIV, and syphilis. ${ }^{3,9}$ The objective of this study was to determine the frequency of $\mathrm{HBsAg}$, $\mathrm{HCV}, \mathrm{HIV}$ and Syphilis in various ABO and Rh (D) blood groups donors. 


\section{Materials and Methods}

In this retrospective study, data of the healthy blood donors obtained from the records of the blood bank of a tertiary care hospital in Chitoor, Andhra Pradesh were analysed. The study was conducted over the period of three and half years (Jan 2014 - May 2017) after obtaining approval from the Institutional Ethical Committee.

Study population included a total of 8260 blood units of both voluntary and replacement donors over a period of 3.5 years. The replacement donors were family members, friends or relatives of the patients concerned. Donors were selected and screened thoroughly as per the standard guidelines of government of India, Drugs and cosmetics act. ${ }^{10}$ Data such as donors age, nature of donor (whether replacement or voluntary), gender and results of screening tests for TTI's were collected.

Sampling Technique: Following informed consent, $5 \mathrm{ml}$ of blood from each donor was used for screening transfusion transmitted infections such as HIV, HBV, HCV and Syphilis. The hepatitis B surface antigen (HBsAg) and Hepatitis $\mathrm{C}$ Virus were tested by $3^{\text {rd }}$ generation ELISA methods. HIV (1and 2) was tested by 3rd \&4th generation ELISA (Tridot) methods using NACO approved commercially available kits. Screening for syphilis wasdone by Rapid Plasma Reagin (RPR) method which detects the presence of treponemal antibodies. The reactive samplewas retested in duplicate before considering it seropositive.

Statistical analysis: The data was collected and analyzed by using Statistical Package for Social Sciences (SPSS) software. Chi square test was applied as test of significance.

\section{Results}

A total of 8260 blood donors were screened for transfusion transmitted infections. Out of the total 8260 blood donors, 4217 (51\%) were voluntary donors and 4043 (49\%) were replacement donors. On sex distribution, very higher percentage for male population constituting $98.8 \%$ and $98.9 \%$ were noted for both voluntary and replacement blood donors respectively. Female accounted for around $1 \%$ in both the donor groups. (Table 1 )

In the present study, Sero-positivity for TTIs was found consistent from 2014 to 2017 and it was found to be statistically significant $(\mathrm{P}<0.05)$. Yearly distribution of TTIs among blood donors are shown in Table 2 .

The overall prevalence of HIV, HBV, HCV and Syphilis was found to be $0.06 \%, 2.1 \%, 0.15 \%$ and $0.4 \%$ respectively. The highest percentage of prevalence was observed for HBV, followed by syphilis, HCV and HIV in decreasing order $(\mathrm{p}<0.05)$. The Hepatitis B had shown a static phase in the first two years and then a decreasing trend over a period of time whereas syphiliswas found more in the year 2016 (Figure 1).

Age, sex and donors distribution of TTI's positive blood donorswere described in Table 3. The majority of TTIs were found positive among male donors representing $98.7 \%$ of the TTI cases. TTI positive replacement blood donors were found in majority constituting $60.7 \% .51 .7 \%$ of blood donors belonging to age group of 18-30 years showed positivity for TTI's followed by $31-40$ years of age group (37\%).

Table 1: Year \& Gender wise distribution of Blood Donors (Voluntary and replacement)

\begin{tabular}{|c|c|c|c|c|c|c|c|}
\hline \multirow[t]{2}{*}{ Year } & \multicolumn{3}{|c|}{ Voluntary donors } & \multicolumn{3}{|c|}{ Replacement donors } & \multirow{2}{*}{$\begin{array}{l}\text { Total Blood } \\
\text { donors }\end{array}$} \\
\hline & Male & Female & Total & Male & Female & Total & \\
\hline 2014 & 1177 & 20 & 1197 & 986 & 7 & 993 & 2190 \\
\hline 2015 & 983 & 7 & 990 & 972 & 17 & 989 & 1979 \\
\hline 2016 & 1064 & 14 & 1078 & 1029 & 15 & 1044 & 2122 \\
\hline 2017 (till May) & 946 & 6 & 952 & 1012 & 5 & 1017 & 1969 \\
\hline Total & $4170(98.8 \%)$ & $47(1.1 \%)$ & $4217(51 \%)$ & $3999(98.9 \%)$ & $44(1.0 \%)$ & $4043(48.9 \%)$ & $8260(100 \%)$ \\
\hline
\end{tabular}

Table 2: Yearly distribution of sero reactive cases

\begin{tabular}{|c|c|c|c|c|c|c|c|c|c|}
\hline \multirow[t]{2}{*}{ Year } & \multicolumn{2}{|c|}{ HIV } & \multicolumn{2}{|c|}{ HBV } & \multicolumn{2}{|c|}{ HCV } & \multicolumn{2}{|c|}{ Syphilis } & \multirow[t]{2}{*}{ Total } \\
\hline & VD & $\mathrm{RD}$ & VD & $\mathrm{RD}$ & VD & $\mathrm{RD}$ & VD & RD & \\
\hline Jan - Dec 2014 & - & 1 & 16 & 42 & 4 & 2 & - & 7 & 72 \\
\hline Jan - Dec 2015 & - & 2 & 29 & 36 & 2 & 2 & - & 3 & 74 \\
\hline Jan - Dec 2016 & - & 1 & 12 & 38 & 1 & 1 & 6 & 13 & 72 \\
\hline Jan -May 2017 & - & 1 & 2 & 6 & - & 1 & - & 4 & 14 \\
\hline \multirow{2}{*}{ Total } & 0 & 5 & 59 & 122 & 7 & 6 & 6 & 27 & 232 \\
\hline & \multicolumn{2}{|c|}{$5(0.06 \%)$} & \multicolumn{2}{|c|}{$181(2.1 \%)$} & \multicolumn{2}{|c|}{$13(0.15 \%)$} & \multicolumn{2}{|c|}{$33(0.4 \%)$} & \\
\hline
\end{tabular}


Table 3: Age, sex and donors distribution of TTI's positive blood donors

\begin{tabular}{|c|c|c|c|c|c|c|}
\hline Character & Donors & HIV & HBsAg & $\mathrm{HCV}$ & Syphilis & Total \\
\hline \multirow[t]{2}{*}{ Sex } & Male: 8169 (99.1\%) & 5 & 179 & 13 & 32 & 229 \\
\hline & Female: $91(0.8 \%)$ & - & 2 & - & 1 & 3 \\
\hline \multirow[t]{2}{*}{ Donors } & Voluntary : 4460 & 1 & 77 & 4 & 9 & 91 \\
\hline & Replacement: 4499 & 4 & 104 & 9 & 24 & 141 \\
\hline \multirow{3}{*}{ Age } & $18-30$ years & 3 & 96 & 11 & 10 & 120 \\
\hline & 31 - 40 years & 2 & 74 & 1 & 9 & 86 \\
\hline & $>40$ years & - & 11 & 1 & 14 & 26 \\
\hline
\end{tabular}

Table 4: The prevalence of TTIs as reported in various studies within India.

\begin{tabular}{|c|c|c|c|c|c|}
\hline Studies & Donors & HIV\% & HbsAg\% & HCV\% & VDRL \% \\
\hline Leena $2012^{12}$ & Karimnagar & 0.27 & 0.71 & 0.14 & 0.10 \\
\hline Chaudhary $2013^{13}$ & Western UP & 0.27 & 1.93 & 1.02 & 0.16 \\
\hline Mehta $2013^{14}$ & Jamnagar & 0.3 & 1.2 & 0.26 & 0.5 \\
\hline Naskar S $2013^{15}$ & Kolkata & 0.28 & 1.75 & 0.37 & 0.44 \\
\hline Geta Negi $2014^{16}$ & Uttarakhand & 0.2 & 1.2 & 0.9 & 0.3 \\
\hline Kaure H $2014^{17}$ & Amritsar & 0.16 & 0.75 & 1.75 & 0.67 \\
\hline Present study & Chitoor, AP & 0.06 & 2.1 & 0.15 & 0.4 \\
\hline
\end{tabular}

Table 5: The prevalence of TTIs as reported in various studies of other countries.

\begin{tabular}{|c|c|c|c|c|c|}
\hline Studies & Donors & HIV\% & HbsAg\% & HCV\% & VDRL\% \\
\hline Khedmat $2007^{18}$ & Iran & 0.003 & 0.487 & 0.093 & 0.005 \\
\hline Ahmad MU $2009^{19}$ & Bangladesh & 0.008 & 1.39 & 0.024 & - \\
\hline Shrestha $2009^{20}$ & Nepal & 0.12 & 0.47 & 0.64 & 0.48 \\
\hline Zheng X $2015^{21}$ & China & 0.15 & 0.51 & 0.25 & - \\
\hline Zameer M $2017^{22}$ & Pakistan & 0.11 & 1.59 & 3.85 & 2.08 \\
\hline Present study & AP,India & 0.06 & 2.1 & 0.15 & 0.4 \\
\hline
\end{tabular}

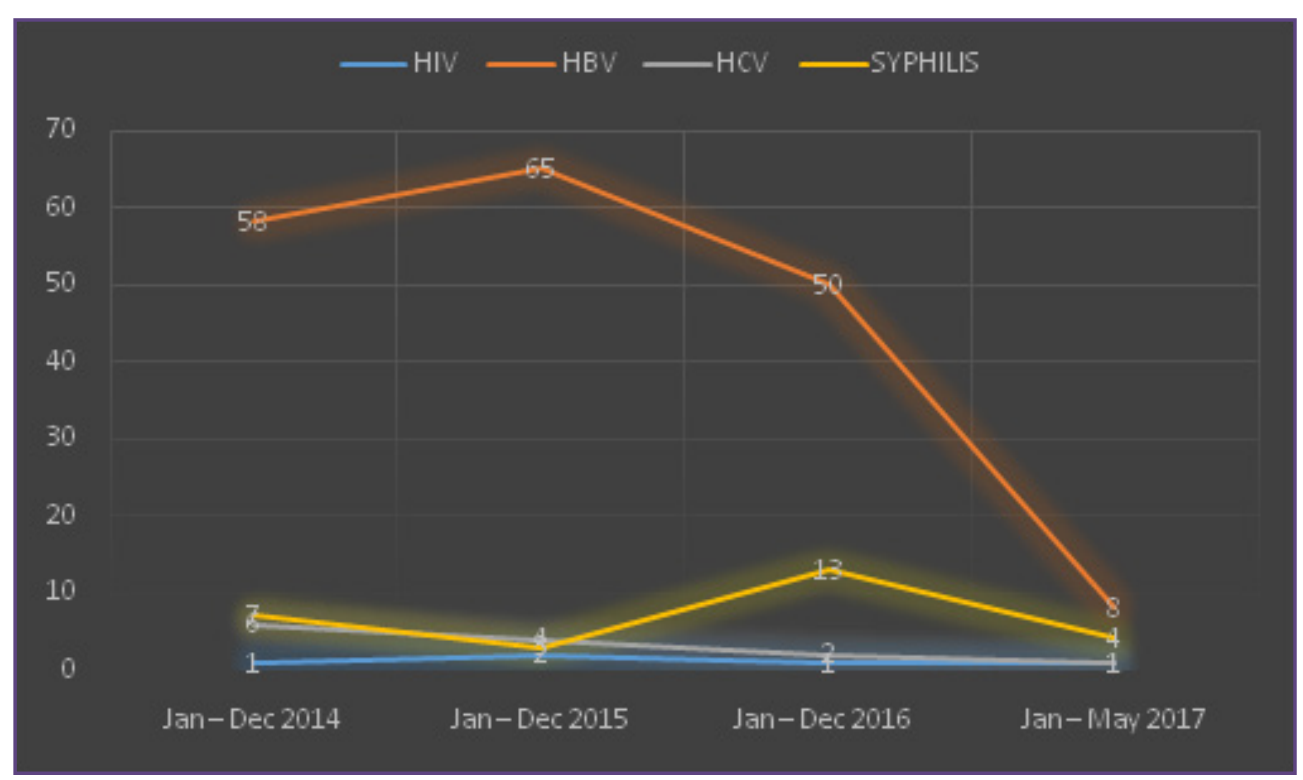

Fig. 1: Yearly Distribution of Seoreactive cases 


\section{Discussion}

Blood transfusion is a life-saving process and helps countless people worldwide.Transfusion transmitted Infections (TTI's) continue to be a potential threat and affect the safety blood transfusion practices especially in developing and under developed countries.

Demographic profile of the present study showed almost equal distribution of both voluntary and replacement donors unlike various other studies which showed increased percentage of replacement donors when compared to voluntary donors. ${ }^{3,11}$ Donor motivation programmes comprising of motivational speeches, telephonic calls to registered voluntary blood donors , continuing medical education has been cited as the reasons for increase in voluntary blood donors.Female donors constituted less than $1 \%$ of cases in our study. This was similar to the studies of Bhawani Y et al(10.52\%) and Pahuja A et al(2.76\%). ${ }^{3,11}$

Various social and economic factors like less awareness about nutrition, lower literacy rate, misconceptions about blood donations have been implicated.

The prevalence of TTIs as reported in various studies on blood donors is depicted in Table 4 and 5. According to the report of National Aids Control Organization, higher incidence of HIV was found in the states of South India and Maharashtra. ${ }^{6}$ Even the studies done within India showed higher prevalence when compared to the present study $(0.06 \%)$. $^{12-17}$

Studies conducted by Khedmatet $\mathrm{al}^{18}(0.003 \%)$ in Iran and Ahmadet $\mathrm{al}^{19}(0.008 \%)$ in Bangladesh showed lesser prevalence of HIV while variable results of $0.12 \%, 0.15 \%$ and $0.11 \%$ have also been reported in various other studies conducted in Nepal, China and Pakistan respevtively. ${ }^{20,21,22}$

Prevalence of HBsAg in our blood donor population was $2.1 \%$ which was contrary to the findings of other studies. ${ }^{12,14,16,18-21}$ Studies by Chaudhary et al(1.93\%) in western UP, Naskar et al $(1.75 \%)$ in northern India, andZameeret al (2.9\%) in Pakistan showed similar findings when compared to the present sudy. ${ }^{13,15,22}$ Detection of the IgM class of antibodies to the hepatitis B core antigen (Anti $\mathrm{HBc}-\mathrm{IgM})$ as an adjuvant marker can be used to confirm recent infection of $\mathrm{HBV}$ so that the higher prevalence of HBsAg among blood donors can be reduced.

From our study, the prevalence rate of $\mathrm{HCV}$ was 0.15 $\%$, which was low when compared with studies of Chaudhary et al (1.02\%), Kaure et al (1.75\%) and Zameer et al $(3.85 \%){ }^{13,17,22}$ The low prevalence of $\mathrm{HCV}$ when compared with HBV might be due to the fact that HCV is less infective when compared with $\mathrm{HBV}$ and $\mathrm{HCV}$ is transmitted mainly through transfusion of blood or blood products, intravenous drug abuse and needle sharing which may not be common in southern part of Andhra Pradesh.

Prevalence of syphilis in the present study was almost similar when compared to other Indian studies. ${ }^{12-17}$ Study conducted in Iran showed the least prevalence of syphilis $(0.005 \%)$ while the study conducted in Pakistan showed higher percentage of prevalence of syphilis $(2.08 \%){ }^{18,22}$

Significant prevalence of TTIs was noted in sexually active young age groups between 18 -30 years which was similar to the study conducted by Leena et al in South India. ${ }^{12}$ Also it was noted that there was significant prevalence of about $60.7 \%$ of TTI's were found occurring in replacement donors and that could be prevented by conducting various awareness programs to motivate safe voluntary donors instead of replacement donors. Number of TTI's cases can also be brought down by using higher sensitivity tests like Nuclei acid amplification testing (NAT) for HIV and HCV, detection of antibodies to core antigen ( $\mathrm{HBcAg}$ ) and $\mathrm{IgM}$ for $\mathrm{HBsAg}$.

\section{Conclusion}

Several efforts should be made to increase the voluntary blood donations such as awareness and motivational programs for safe voluntary blood donation, health compaigns and encouragement of female donors for blood donation. Following strict donor eligibility criteria and effecting high sensitive screening methods can bring down the prevalence of TTI's. Proper treatment and follow-up counselling can help in preventing further transmission of infections in the community.

\section{Acknowledgements}

Authors sincerely thank Professor Dhananjay S Kotasthane, for his constant support. Authors also acknowledge the colossal help received from the scholars whose articles are cited in this manuscript. The authors are also grateful to authors/editors/ publishers of all those articles, journals and books from where the literature for this article has been reviewed and discussed.

\section{References}

1. Jasani J, Patel V, Bhuva K, vavachhani A, Patel H, Falleir J, et al. Sero-prevalence of transfusion transmissible infections among blood donors in a tertiary care hospital. Int J Biol Med Res. 2012; 3(1): 1423-25.

2. Widman FK, Technical Manual America Association of Blood Bank, Anglington USA;1985, PP 325-344.

3. Bhawani Y, Rao PR, Sudhakar V. Seroprevalence of transfusion transmissible infections among blood donors in a tertiary care hospital of Andhra Pradesh. Biology and Medicine 2010;2:45-8. 
4. Schreiber GB, Busch MP, Kleinman SH, Korelitz JJ. Therisk of transfusion-transmitted viral infections. N Engl J Med1996;334:1685-90.

5. Giri PA, Deshpande JD, Phalke DB, Karle LB:Seroprevalence of transfusion transmissible infections among voluntary blood donors at a tertiary care teaching hospital in rural area of India: J.Fam. Med. Primary Care 2012: 1:48-51.

6. Singh N. NAT: Safe Blood, Safe India. Available from: http://www.expresshealthcare.in/200810/knowledge02. shtml. [Last cited on 2010, Jun 14].

7. Lavanchy D. Hepatitis B virus epidemiology, disease burden,treatment, and current and emerging prevention and control measures:A review. J Viral Hepat 2004,11:97-107.

8. Gasiorowicz M, Hurrie M, Russel A, Hoxie N, Vegeront J. Epidemiologictrends in infection, mortality and transplants related to hepatitis C inWisconsin. WMJ 2006;105:34-9.

9. World Health Organization (WHO). Blood Safety Strategy for the African Region. Brazzaville,World Health Organization, Regional Office for Africa(WHOAFR / RC51/9 Rev.1). 2002.

10. Government of India. Drugs and Cosmetics Act. The Gazette of India, New Delhi. 1989.

11. Pahuja S, Sharma M, Baitha B, Jain M. Prevalence and trends of markers of Hepatitis $\mathrm{C}$ virus, Hepatitis $\mathrm{B}$ virus and Human immunodeficiency virus in Delhi blood donors: A hospital based study. Jpn J Dis 2007;60;389-91.

12. Leena MS, Shafe M. Trend and prevalence of transfusion transmitted infections among blood donors in rural teaching institute, South India. Journal of Pathology of Nepal. 2012;2:203-206.

13. Chaudhary V, Agrawal VK, Sexena SK, Upadhyay D, Singh A, Singh SP. Seroprevalence of common transfusion transmissible infections among blood donors in western Uttar Pradesh, India. Int J Med Sci Public Health 2014;3:1381-1384.

14. Mehta D, Vachhani JH, Desai NJ. Seroprevalence of HIV, HBV,HCV and syphilis in blood donors.Indian Journal of Research, 2013;2:2:240-241.
15. Naskar S, Nandy S, Basu K, Basu R. Study of Seroprevalence of HIV, Hepatitis B and C And Syphilis Among Blood Donors In A Tertiary Care Hospital, Kolkata. IOSR Journal of Dental and Medical Sciences. 2013; 11(3): 63-6.

16. Negi G, Gaur DS. Trends of Transfusion Transmissible Diseases Among Blood Donors at Uttarakhand, India. Indian Journal of Community Medicine: Official Publication of Indian Association of Preventive \& Social Medicine. 2014;39(3):183-186.

17. Kaur H, Mannan R, Manjari M. Seroprevalence of the Blood Borne Infection in Blood Donors: Our 11 Year (2001-2011) Experience in a Tertiary Care Teaching Hospital at Amritsar (Punjab). International Journal of Advanced Research. 2014; 6(2): 967-72.

18. Khedmat H, Fallahian F, Abolghasemi H, Alavian SM, HajibeigiB, Miri SM, et al. Seroepidemiologic study of hepatitis $B$ virus, hepatitis $C$ virus, human immunodeficiency virus and syphilis infections in Iranian blood donors. Pak J Biol Sci. 2007; 10(24): 4461-6.

19. Ahmed MU, Begum HA, Hossain T, Chakraborty P. Incidence of common transfusion transmitted diseases among blood donors. Journal of Armed Forces Medical College, Bangladesh. 2009; 5(1): 4-6.

20. Shrestha AC, Ghimire P, Tiwari BR, Rajkarnikar M. Transfusion-transmissible infections among blood donors in Kathmandu,Nepal. The Journal of Infection in Developing Countries. 2009; 3(10): 794-7.

21. Zheng X, Ding W, Li G, Wu Y, Wu D, Zhu H, et al. Seroprevalence of transfusion-transmissible infectious agents among volunteer blood donors between 2006 and 2012 in Zhejiang, China. Blood Transfusion. 2015; 13(3): 401.

22. Zameer M, Shahzad F, Shafi Khan F, Ali H, Saeed U, Farooq M. Transfusion transmissible infections among healthy blood donors at blood bank from children's hospital \& institute of child health Lahore. Pak Armed Forces Med J 2017; 67(1):131-36.

*Corresponding author:

Nafeesa Banu S, Assistant Professor, Dept. of Pathology, Mahatma Gandhi Medical college and Research Institute, Pondicherry, India

Phone: +91 9500050960

Email: drnafeesabanu@gmail.com

Date of Submission : 18.09.2017

Date of Acceptance : 14.10.2017

Financial or other Competing Interests: None.

Date of Publication : 28.01.2018 